\title{
Avaliação da ação afirmativa no vestibular da UFBA
}

\author{
LILIA CAROLINA CARNEIRO DA COSTA* \\ JESSICA PRISCILA RIVAS DOS SANTOS** \\ ANTONIO GUIMARÁES*** \\ NADYA ARAUJO GUIMARÁES ${ }^{* * * *}$
}

\section{RESUMO}

Com o objetivo de tornar o ensino superior acessível a todos, independentemente da classe social ou etnia, as universidades públicas vêm implantando açôes afirmativas. A partir de 2005, o vestibular da Universidade Federal da Bahia (UFBA) possui um sistema de cotas que reserva cerca de $45 \%$ das vagas para candidatos originários de escola pública que se declaram pretos, pardos, índio-descendentes ou de outros grupos étnicos. Assim, desejando verificar as mudanças ocorridas no vestibular, em razão do sistema de cotas, este estudo utiliza dados da UFBA, de 2003 a 2008, e analisa a relação existente entre a aprovação no vestibular e as características dos candidatos, como renda familiar, cor/raça e nível educacional dos pais, entre outras variáveis. Mediante modelos logísticos ajustados a cada característica do candidato, foi observado que o sistema de cotas aumentou as chances de aprovaçáo para os candidatos com

* Professora Assistente do Departamento de Estatística da Universidade Federal da Bahia (UFBA) (liliacosta@ufba.br).

** Aluna do Curso de Estatística da Universidade Federal da Bahia (UFBA) (jeu-rivas@hotmail.com). *** Professor Titular do Departamento de Sociologia da Universidade de Sáo Paulo (USP) (asergioguimaraes@me.com).

**** Professora Titular do Departamento de Sociologia da Universidade de São Paulo (USP) (nadya@usp.br). 
renda familiar de 1 a 5 salários mínimos, que estudaram em escola estadual no $2^{\circ}$ grau, e que trabalharam enquanto cursavam o ensino médio, entre outras variáveis. Já com o modelo logístico múltiplo, foi observado principalmente que a variável raça/cor apresentou uma tendência à equidade ao longo dos anos, isto é, independentemente da etnia, os candidatos tendem a ter as mesmas chances de serem aprovados no vestibular.

Palavras-chave: Ação afirmativa, Universidades públicas, Sistema de cotas, Raça.

\section{RESUMEN}

Con el objetivo de tornar la enseńanza superior accesible a todos, independientemente de la clase social o etnia, las universidades públicas vienen implementando acciones afirmativas. Desde 2005, el examen de ingreso de la Universidad Federal de Bahía (UFBA) posee un sistema de cuotas que reserva cerca del $45 \%$ de los cupos para aspirantes provenientes de las escuelas públicas que se declaren negros, mulatos, descendientes de indios o de otros grupos étnicos. Así, con el propósito de verificar los cambios ocurridos en el examen de ingreso, por causa del sistema de cuotas, este estudio utiliza datos de la UFBA, del 2003 al 2008, y analiza la relación existente entre la aprobación del examen y las características de los aspirantes, como renta familiar, color/raza y nivel educacional de los padres, entre otras variables. Mediante modelos logísticos que se ajustan a cada característica del candidato, se observó que el sistema de cuotas aumentó las posibilidades de ingreso de los aspirantes con renta familiar de uno a cinco sueldos mínimos; de los que hicieron el secundario en escuelas públicas estaduales; y de los que trabajaban mientras cursaban la enseñanza media, entre otras variables. Ya con el modelo logístico múltiple, se observó principalmente que la variable raza/color presentó una tendencia a la equidad a lo largo de los años, es decir, independientemente de la etnia, los aspirantes tienden a tener las mismas chances de ser aprobados en el examen de ingreso.

Palabras clave: Acciones afirmativas, Universidades públicas, Sistema de cuotas, Raza.

\section{ABSTRACT}

Public universities have been implanting affirmative actions with the objective of giving everybody access to higher education. The quota system at UFBA began in 2005 and sets aside about $45 \%$ of vacancies to candidates from public schools who declare themselves black, brown, descendants of Indians or belonging to other ethnic groups. In order to study the changes in the selection process resulting from the quota system, this study used data of entrance records at UFBA from 2003 to 2008 and analyzed the relationship between those approved and certain characteristics of the candidates, such as family income, color/race and educational level of the parents, among other variables. According to simple logistic models, the chances of passing/entering increased with the quota system for candidates who have a family income from one to five minimum salaries, who studied at state high schools and who worked while studying. However, according to multiple logistic models, the main result is that race/color tended to equity over the years, that is, candidates tend to have the same chances of entering university, regardless of their ethnicity.

Keywords: Affirmative action, Public universities, Quota system, Race.

68 - Est. Aval. Educ., São Paulo, v. 21, n. 45, p. 67-86, jan./abr. 2010 


\section{INTRODUÇÃO}

A educação superior é ainda um privilégio das classes média e alta, no Brasil. O recente aumento de admissóes na graduação (284\% entre 1991 e 2005) expressa um crescimento importante no sistema privado, o qual contabiliza $73 \%$ de todos os registros em 2005 (Brasil, 2005). A instituição pública, entretanto, aplica quase todo o investimento governamental em pesquisa, possui o pessoal mais qualificado $(66 \%$ de todas as universidades em que há doutores trabalhando são públicas) e fornece mais alternativas diversificadas para carreiras futuras, monopolizando amplamente a maioria das carreiras competitivas.

Apesar de muitas melhorias recentes e sendo totalmente livre de taxas, o sistema público permanece altamente seletivo e dominado pelas classes mais altas. Seu exame de admissão, muito competitivo, é uma barreira para aqueles oriundos de escolas públicas, as quais geralmente oferecem um ensino de má qualidade. Além disso, suas condiçôes operacionais (poucas oportunidades de cursos noturnos e sistema de bolsas de estudo restrito) limitam as chances daqueles que têm que conciliar estudo e trabalho. Por essa razão, as universidades públicas continuam sendo mecanismo de reprodução de classe e status no Brasil contemporâneo.

Pensando nisso, em 2005, a Universidade Federal da Bahia implementou um sistema de cotas em que $36,55 \%$ das vagas são destinadas aos candidatos de escola pública que se declaram pretos ou pardos; $6,45 \%$ são para os candidatos de escola pública de qualquer etnia ou cor; $2 \%$ para índio-descendentes de escola pública e $55 \%$ para todos os candidatos de qualquer procedência escolar, etnia ou cor. Utilizando dados do vestibular de 2005 a 2008 e mediante modelos logísticos, este estudo verificou o impacto do sistema de reserva de vagas na aprovação do vestibular de candidatos com diferentes características pessoais, educacionais e profissionais.

\section{MODELOS LOGÍSTICOS SIMPLES}

Com a finalidade de estudar quais características dos candidatos têm relação com o seu sucesso no vestibular, primeiramente foram ajustados modelos logísticos para cada variável independente, e, depois, todas as variáveis significativas foram inseridas em um modelo mais amplo. A variável dependente foi a aprovação ou não no vestibular. Como o estudo contempla muitas covariáveis, as mesmas foram agrupadas em 5 categorias, a saber: Característica Socioeconômica, Características dos Pais, Características antes da Universidade, Características com Respeito à Universidade e Características Pessoais. Assim, utilizando a abrangência apresentada por Dachs e Maia (2006), as variáveis foram inseridas no modelo, seguindo a ordem das categorias, permitindo verificar se a 
“influência” de variáveis de um nível superior é "canalizada” até o resultado de interesse, analisando a perda de significância de um ou mais das variáveis.

Além disso, este estudo também tem como objetivo verificar o impacto do sistema de cotas na aprovação dos candidatos por diferentes características. Para isso, foi necessário considerar o ano de inscrição do candidato no vestibular. Pode-se observar na figura 1 que, de maneira geral, a aprovação no vestibular vem aumento ao longo dos anos. Entretanto, foi verificado, ainda, que existe uma relação linear entre 2003 e 2004 com o percentual de aprovaçáo no vestibular; já com o sistema de cotas, pode-se notar uma relaçáo quadrática entre os anos e o percentual de aprovação. Mesmo supondo que 2005 é atípico, visto que foi o ano de implementação do sistema de cotas, ainda assim a inclinação da reta entre 2003 e 2004 é menor que entre 2006 e 2008, revelando que nesses três últimos anos a média de aprovação por ano vem crescendo.

Figura 1 - Percentual de candidatos aprovados no vestibular por ano de inscrição

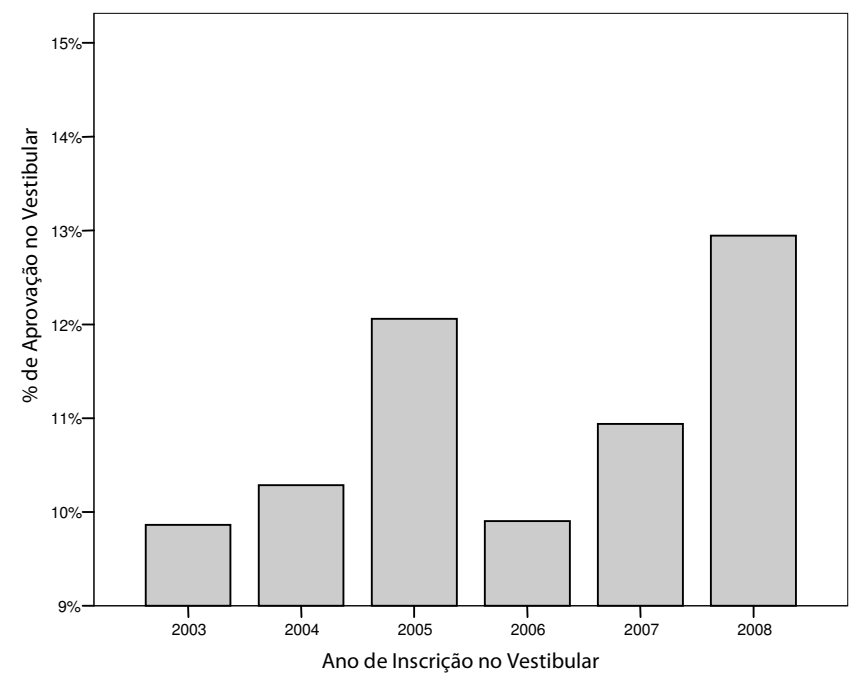

\section{Característica Socioeconômica}

A tabela 1 mostra que quanto maior a renda familiar, maior é a probabilidade de aprovação no vestibular. Foi ajustado um modelo com renda, ano de inscrição e um termo de iteraçáo entre essas duas covariáveis, o qual foi significativo (valor de $\mathrm{p}=0$ ). Pôde-se perceber que as diferenças nas chances de aprovação no vestibular, entre os diferentes níveis de renda, vêm diminuindo ao longo do tempo. Em 2004, por exemplo, o candidato com renda acima de 20 salários mínimos tinha cerca de

70 • Est. Aval. Educ., São Paulo, v. 21, n. 45, p. 67-86, jan./abr. 2010 
5,5 vezes mais chances de ser aprovado no vestibular que um candidato com renda familiar até 1 salário mínimo. Em 2008, porém, essa chance cai para 1,8 vezes. Portanto, o vestibular apresenta uma tendência à equidade, isto é, todos os candidatos tendem a ter a mesma chance de aprovaçáo, independentemente da renda familiar - qualidade esta desejada em toda avaliação.

\section{Características dos Pais}

Foram consideradas as seguintes características nessa categoria: nível educacional do pai, nível educacional da mãe, tipo de ocupação do pai e tipo de ocupação da máe. Todas essas variáveis foram significativas e tiveram um resultado esperado, ou seja, quanto maior o valor dessas características, maiores são as chances de aprovação no vestibular. Além disso, os termos de iteração entre cada uma dessas variáveis e o ano de inscrição também foram significativos.

Quando construído um modelo para cada ano, foi possível observar, na variável "nível educacional do pai", que as categorias "ensino médio completo", "superior incompleto" e "superior completo" foram significativas (valor de $\mathrm{p}$ menor que 5\%), em 2003 e 2004. Entretanto, a partir de 2005, quando foi implementado o sistema de cotas, apenas a variável "nível superior completo" foi significativa. Para todas essas variáveis, também foi possível observar uma tendência à equidade no vestibular.

Utilizando os métodos de seleção de modelos: backward e forward, o modelo encontrado possui as seguintes variáveis: nível educacional da mãe, tipo de ocupação do pai e da mãe.

\section{Características antes da Universidade}

Os candidatos responderam várias questôes sobre sua vida educacional além de outras informaçóes profissionais, a saber: turno em que cursou o $1^{\circ}$ grau, rede de ensino em que estudou o $2^{\circ}$ grau, local de conclusão do $2^{\circ}$ grau, turno em que cursou o $2^{\circ}$ grau, quando concluiu o $2^{\circ}$ grau, tipo do curso de $2^{\circ}$ grau, trabalhou durante os estudos, participação econômica, carga horária de trabalho, quem é o chefe da família, situação profissional do cônjuge, e principal ocupação. Apenas a variável "principal ocupação" não apresentou relação significativa com a aprovaçẫo no vestibular. Para as demais variáveis, os termos de iteração com o ano de inscrição também foram significativos.

Ajustando o modelo para cada ano e observando a variável "rede de ensino do $2^{\circ}$ grau", verifica-se que, a partir de 2005, praticamente só os candidatos oriundos das Es- 
colas Federais têm mais chances de aprovação no vestibular. Quanto à variável "chefe de família”, não foi significativa em 2003 e 2005 e, nos demais anos, os candidatos que têm o cônjuge como chefe da família têm menos chances de aprovação no vestibular. As variáveis que apresentaram uma tendência à equidade no vestibular foram "local de conclusão do $2^{\circ}$ grau", "trabalhou durante os estudos" e "quem é o chefe da família".

Fazendo o procedimento de seleção de modelos, todas as variáveis foram mantidas no modelo com exceção de "participação econômica".

\section{Características com respeito à Universidade}

As variáveis que fazem parte dessa categoria são: número de vezes em que prestou vestibular, se fez cursinho, quem influenciou na escolha do curso, expectativa em relação ao curso superior, pretende trabalhar durante a faculdade, curso escolhido, e ano de inscrição no vestibular. Como a variável "curso escolhido" tem muitas categorias, foi dividida nos seguintes grupos: Exatas, Biológicas e Saúde, Humanas e Letras, Artes. E, em cada grupo, os cursos foram separados em alta, média e baixa concorrência, como apresentado na figura 2.

Figura 2 - Percentual de aprovação no vestibular por curso e por área de estudo

(a) Exatas

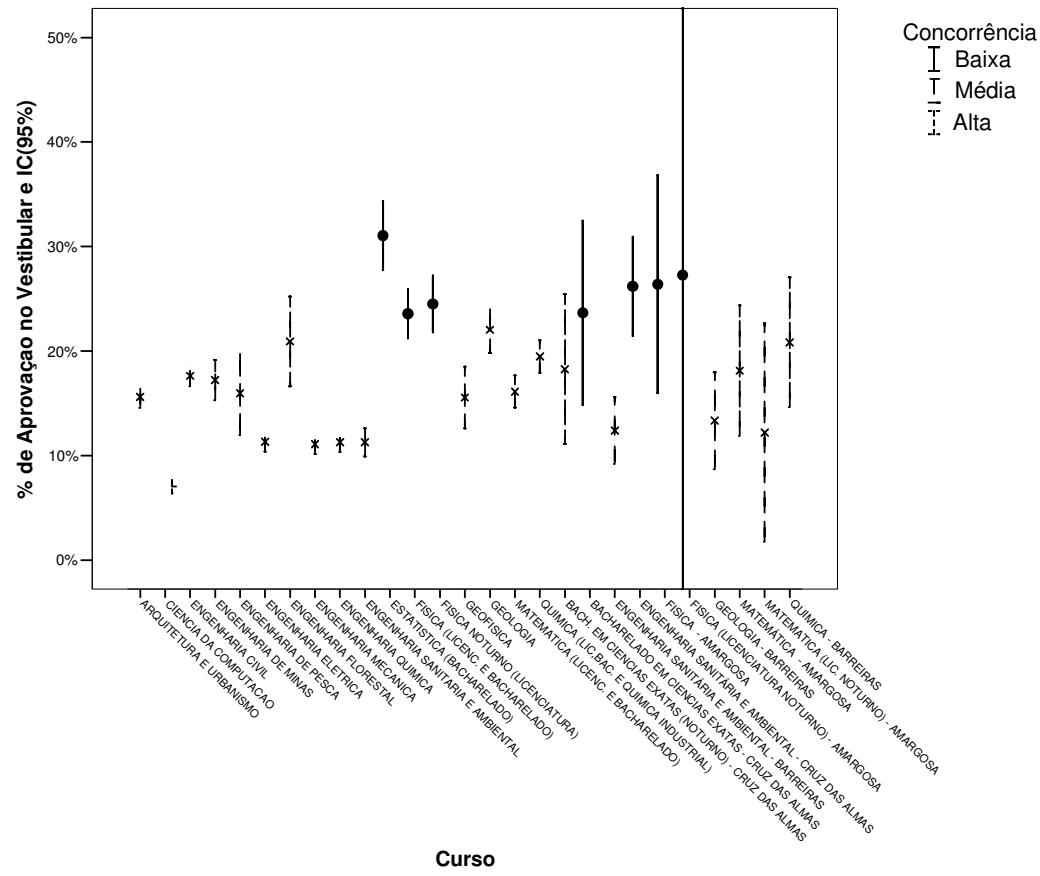

72 - Est. Aval. Educ., São Paulo, v. 21, n. 45, p. 67-86, jan./abr. 2010 
(b) Biológicas e Saúde

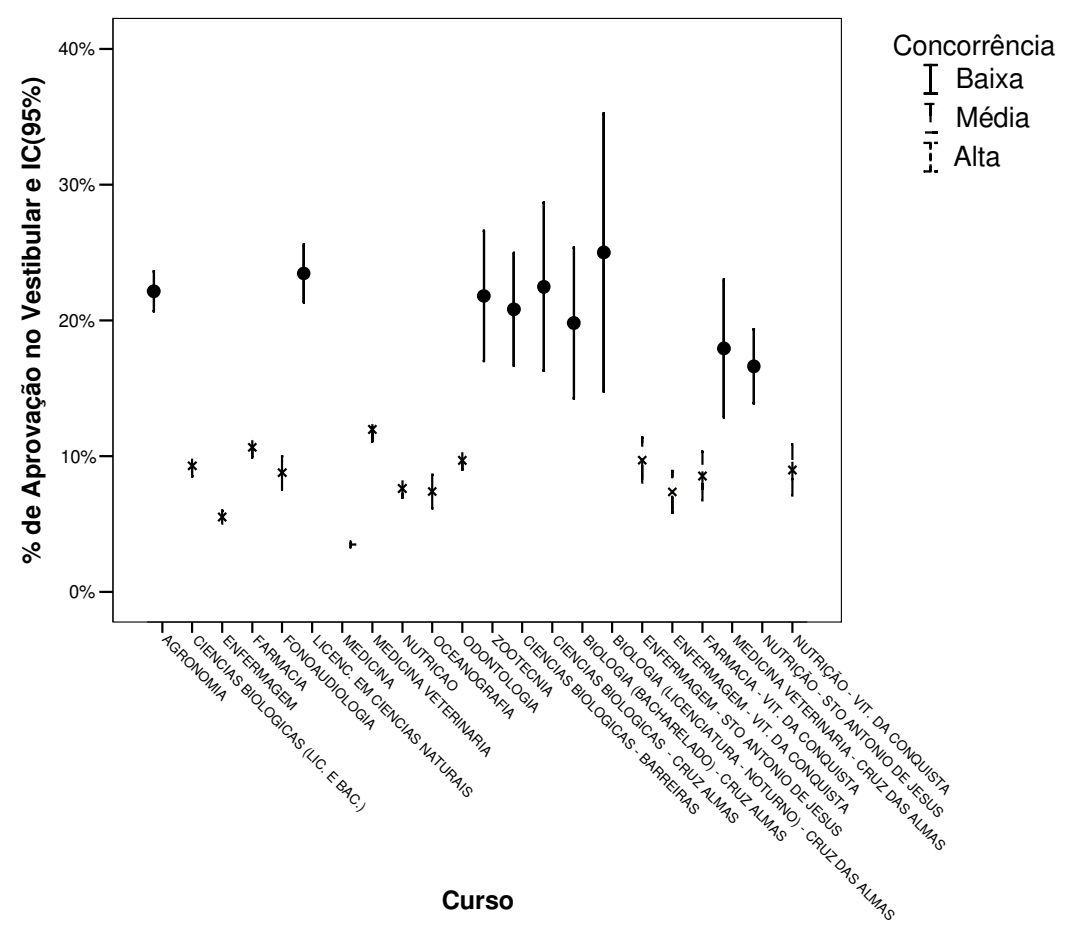

(c) Humanas e Letras

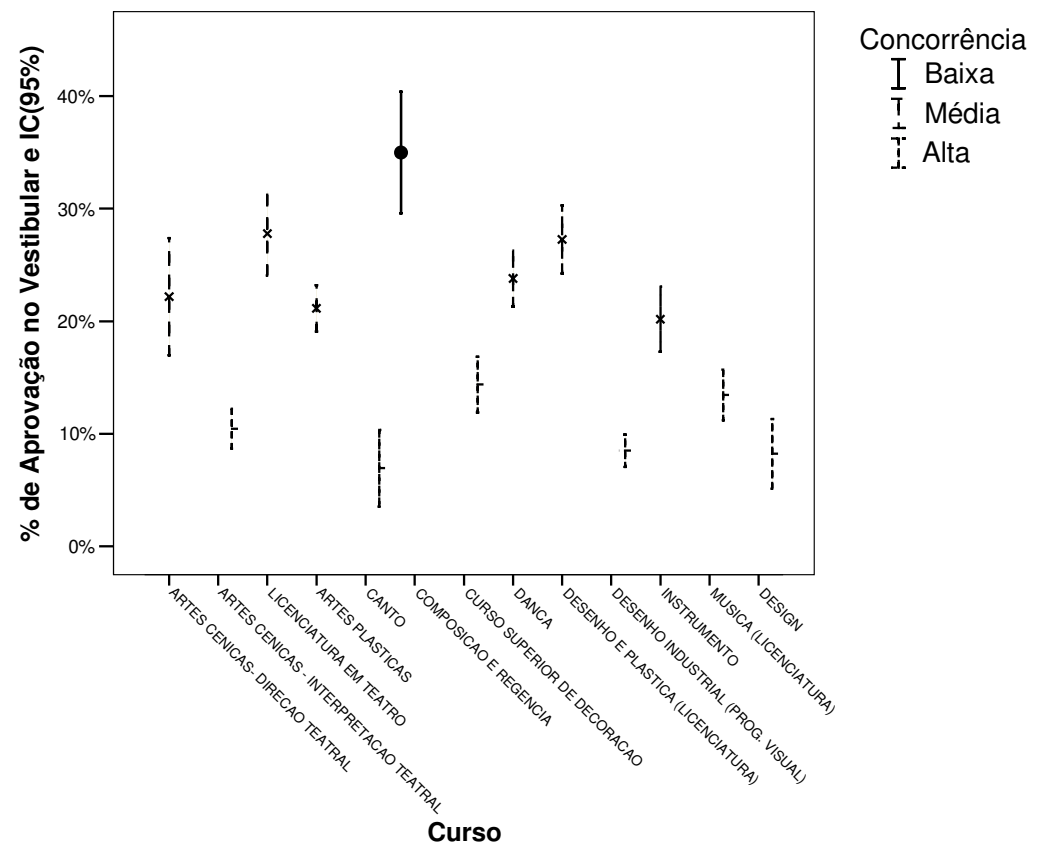

Est. Aval. Educ., São Paulo, v. 21, n. 45, p. 67-86, jan./abr. 2010 • 73 
(d) Artes

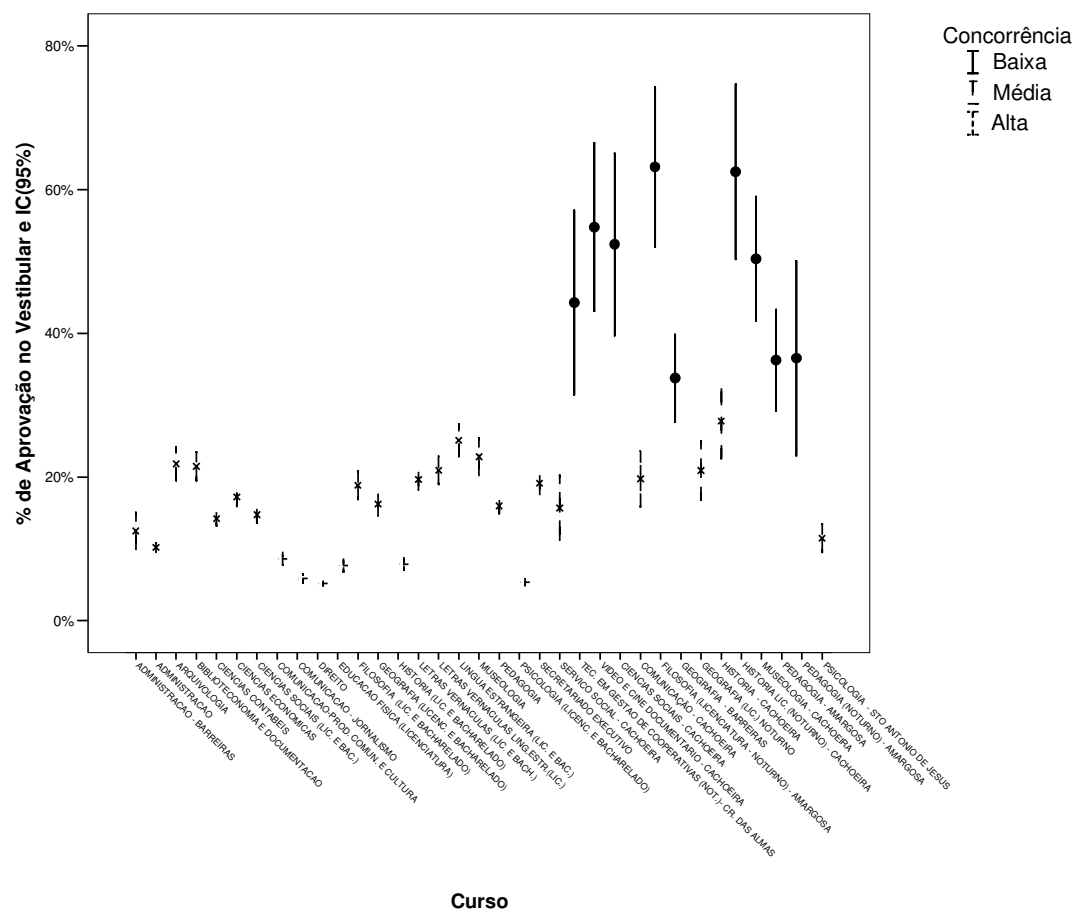

Apenas para a variável "curso escolhido", o termo de iteração com o ano de inscrição no vestibular não foi significativo. Ajustando um modelo para cada ano de inscrição, foi verificado que a variável "fez cursinho" não foi significativa em 2003 e 2004, mas, a partir de 2005, as chances de aprovação foram maiores para os candidatos que fizeram os cursos pré-vestibulares.

Outro resultado interessante foi quanto à variável "expectativa em relação ao curso superior". Em 2003 e 2004, apenas os candidatos que escolheram a opção "outros" tiveram maiores chances no vestibular; enquanto, a partir de 2005, os candidatos que esperavam, com a faculdade, um "aumento de conhecimento, cultura geral e consciência crítica" apresentaram melhores resultados nos vestibulares.

As variáveis que revelaram uma tendência à equidade no vestibular foram: "número de vezes em que prestou vestibular" e "pretende trabalhar durante a faculdade". Mesmo após a utilização dos métodos para seleção de modelos, todas as variáveis permaneceram.

74 • Est. Aval. Educ., São Paulo, v. 21, n. 45, p. 67-86, jan./abr. 2010 


\section{Características Pessoais}

As variáveis que fazem parte dessa categoria são: sexo, idade, estado civil, residência atual, e cor/raça. Apenas a variável "estado civil" não apresentou relação significativa com a aprovação no vestibular, e "sexo" não tem iteração com o ano de inscrição.

\section{MODELO LOGÍSTICO MÚLTIPLO}

Com a finalidade de ajustar um modelo geral, foram inseridas variáveis no modelo de acordo com as categorias descritas anteriormente, isto é, primeiramente a variável "renda familiar" foi incluída no modelo, depois as variáveis da categoria "características dos pais", e assim por diante. A variável "tipo de ocupaçáo do pai" não foi significativa; a variável "tipo de ocupação da mãe" deixou de ser significativa a partir da inclusão das variáveis da categoria "características com respeito à universidade"; e "idade" também não apresentou resultado significativo. Portanto, não incluindo essas variáveis no modelo final, e como a maioria das variáveis apresentaram iteração com o ano de inscrição, foi construído um modelo logístico múltiplo para cada ano (Tabela 1).

Como principais resultados, foram observados que:

- nível educacional da mãe praticamente não apresentou resultado significativo nos modelos;

- turno em que cursou o $1^{\circ}$ grau só foi significativa em 2007;

- quando concluiu o $2^{\circ}$ grau foi significativa em 2003 e 2005;

- turno em que cursou o $2^{\circ}$ grau passou a ser significativa a partir de 2006;

- trabalhou durante os estudos deixou de ser significativa a partir de 2006;

- residência atual não foi significativa em 2007 e 2008;

- cor/raça e rede de ensino de $2^{\circ}$ grau - a partir de 2005 , as diferenças entre as chances de um candidato ser aprovado, das diversas categorias de cor/ raça e rede de ensino, vão diminuindo, até que, em 2008, a variável cor/raça deixa de ser significativa. Por exemplo, a Odds Ratio (Razão de chances) de um aluno da escola federal é de 4,8 em 2005 e de 2,7 em 2008. Já para um candidato de cor branca é de 1,4 em 2005 e de 1,2 em 2007. 
Tabela 1 - Razão de chances para o modelo logístico múltiplo

\begin{tabular}{|c|c|c|c|c|c|c|c|c|c|}
\hline & \multicolumn{2}{|c|}{ Aprovados } & \multicolumn{7}{|c|}{ Modelo Logístico Múltiplo } \\
\hline & Sim & $\%$ & Geral & 03 & 04 & 05 & 06 & 07 & 08 \\
\hline \multicolumn{10}{|l|}{ Renda familiar } \\
\hline Até 1 S.M. & 837 & 6,7 & 1 & 1 & 1 & 1 & 1 & 1 & 1 \\
\hline Maior que 1 até 3 S.M. & 4723 & 9,5 & $1,4^{*}$ & 1 & $1,7^{*}$ & $1,5^{*}$ & $1,5^{*}$ & $1,3^{*}$ & $1,6^{*}$ \\
\hline Maior que 3 até 5 S.M. & 5238 & 10,5 & $1,5^{*}$ & 1,2 & $1,9^{*}$ & $1,8^{*}$ & $1,6^{*}$ & $1,4^{*}$ & $1,7^{*}$ \\
\hline Maior que 5 até 10 S.M. & 5685 & 11,5 & $1,7^{*}$ & 1,2 & $2,2^{*}$ & $1,9^{*}$ & $1,9^{*}$ & $1,8^{*}$ & $2^{*}$ \\
\hline Maior que 10 até 20 S.M. & 3631 & 12,9 & $2^{*}$ & 1,4 & $2,7^{*}$ & $2,3^{*}$ & $1,9^{*}$ & $2^{*}$ & $2,5^{*}$ \\
\hline Maior que 20 S.M. & 2502 & 14,3 & $2,5^{*}$ & $1,8^{*}$ & $3^{*}$ & $2,8^{*}$ & $2,2^{*}$ & $2,5^{*}$ & $2,8^{*}$ \\
\hline \multicolumn{10}{|l|}{ Nível educacional da mãe } \\
\hline Nunca frequentou a escola & 333 & 8,6 & 1 & 1 & 1 & 1 & 1 & 1 & 1 \\
\hline Primário incompleto & 1270 & 8,8 & 0,9 & 0,8 & 0,6 & 0,9 & 0,9 & 1,1 & 0,9 \\
\hline Primário completo & 1012 & 9,7 & 0,9 & 0,8 & 0,6 & 0,8 & 0,9 & 1,2 & 1 \\
\hline Ginasial incompleto & 1414 & 9,4 & 0,9 & 0,8 & 0,6 & 0,7 & 1 & 1,1 & 1 \\
\hline Ginasial completo & 892 & 9,4 & 0,8 & 0,9 & 0,7 & 0,8 & 0,9 & 1 & 0,8 \\
\hline Colegial incompleto & 1210 & 10,2 & 0,9 & 0,9 & $0,6^{*}$ & 1 & 0,8 & 1,2 & 0,9 \\
\hline Colegial completo & 8121 & 10,5 & 0,9 & 0,8 & 0,6 & 0,9 & 1 & 1,2 & 0,9 \\
\hline Superior incompleto & 1766 & 11,2 & 1 & 0,9 & 0,7 & 0,9 & 1,1 & 1,2 & 0,9 \\
\hline Superior completo & 6432 & 13,9 & $1,2^{*}$ & 1 & 1 & 1,1 & 1,4 & $1,5^{*}$ & 1,1 \\
\hline \multicolumn{10}{|l|}{ Turno em que cursou $1^{\circ} \mathrm{grau}$} \\
\hline Sempre noturno & 202 & 6,1 & 1 & 1 & 1 & 1 & 1 & 1 & 1 \\
\hline Sempre diurno & 21087 & 11,2 & $1,4^{*}$ & 1,6 & 0,9 & 1,3 & 1,1 & $2,2^{*}$ & 1,5 \\
\hline Outro & 1378 & 8,3 & 1,2 & 1 & 0,8 & 1,2 & 0,8 & $1,9^{*}$ & 1,3 \\
\hline \multicolumn{10}{|l|}{ Rede de ensino do $2^{\circ}$ grau } \\
\hline Escola Municipal & 679 & 9,5 & 1 & 1 & 1 & 1 & 1 & 1 & 1 \\
\hline Escola Estadual & 7357 & 9,3 & 0,9 & 1,2 & 0,7 & 1 & 0,9 & 1,1 & 0,8 \\
\hline Escola Federal & 2219 & 26,3 & $3,4^{*}$ & $4,2^{*}$ & $2,5^{*}$ & $4,8^{*}$ & $3,1^{*}$ & $3,8^{*}$ & $2,7^{*}$ \\
\hline Escola Particular & 12090 & 11,1 & 0,9 & $2,1^{*}$ & 1,3 & 0,9 & $0,6^{*}$ & 0,8 & $0,7^{*}$ \\
\hline Escola Comunitária & 118 & 12,2 & $1,4^{*}$ & 1,8 & 1,9 & 1,9 & 1,7 & 1,3 & 0,9 \\
\hline Supletivo & 68 & 5 & $0,6^{*}$ & 1,7 & 0,9 & & & & \\
\hline Maior parte em Escola Pública & 149 & 7,3 & $0,7^{*}$ & 1,5 & 0,9 & & & & \\
\hline \multicolumn{10}{|l|}{ Turno em que cursou $2^{\circ}$ grau } \\
\hline Sempre noturno & 853 & 6,7 & 1 & 1 & 1 & 1 & 1 & 1 & 1 \\
\hline Sempre diurno & 20077 & 11,4 & $1,3^{*}$ & 1,1 & 1,3 & 1 & $1,3^{*}$ & $1,4^{*}$ & $1,3^{*}$ \\
\hline Outro & 1716 & 9,7 & 1,1 & 1,2 & 1 & 1 & 1 & 1,2 & 1 \\
\hline \multicolumn{10}{|l|}{ Quando concluiu $2^{\circ}$ grau } \\
\hline Este ano & 6962 & 8,9 & 1 & 1 & 1 & 1 & 1 & 1 & 1 \\
\hline O ano passado & 5297 & 11,8 & 0,9 & $1,3^{*}$ & 1 & 0,9 & 0,9 & 0,9 & 0,9 \\
\hline Há dois anos & 3305 & 12,5 & 0,9 & $1,4^{*}$ & 1 & $0,7^{*}$ & 0,9 & 0,9 & 0,9 \\
\hline Há três anos & 1773 & 12,1 & 0,9 & 1,1 & 1 & $0,8^{*}$ & 0,8 & 0,8 & 0,8 \\
\hline Há mais de três anos & 6743 & 12,3 & 1 & $1,3^{*}$ & 0,9 & $0,7^{*}$ & 0,9 & 0,9 & 0,9 \\
\hline \multicolumn{10}{|l|}{ Tipo do curso de $2^{\circ}$ grau } \\
\hline Colegial & 18669 & 11,2 & 1 & 1 & 1 & 1 & 1 & 1 & 1 \\
\hline Técnico & 1994 & 12,7 & $0,8^{*}$ & 0,8 & 1 & $0,8^{*}$ & $0,8^{*}$ & $0,8^{*}$ & 0,9 \\
\hline Magistério & 799 & 9,2 & $0,8^{*}$ & $0,7^{*}$ & $0,7^{*}$ & 0,9 & $0,7^{*}$ & 0,9 & 0,8 \\
\hline Suplência & 425 & 6,3 & $0,5^{*}$ & $0,4^{*}$ & $0,3^{*}$ & $0,7^{*}$ & $0,6^{*}$ & $0,6^{*}$ & $0,5^{*}$ \\
\hline Outros & 787 & 8,1 & $0,7^{*}$ & $0,7^{*}$ & 0,7 & $0,7^{*}$ & $0,7^{*}$ & $0,6^{*}$ & $0,7^{*}$ \\
\hline
\end{tabular}

76 - Est. Aval. Educ., São Paulo, v. 21, n. 45, p. 67-86, jan./abr. 2010 


\begin{tabular}{|c|c|c|c|c|c|c|c|c|c|}
\hline & \multicolumn{2}{|c|}{ Aprovados } & \multicolumn{7}{|c|}{ Modelo Logístico Múltiplo } \\
\hline & Sim & $\%$ & Geral & 03 & 04 & 05 & 06 & 07 & 08 \\
\hline \multicolumn{10}{|l|}{ Trabalho durante os estudos } \\
\hline $\begin{array}{l}\text { Sim, durante a educação } \\
\left.\text { básica ( } 1^{\circ} \text { e } 2^{\circ} \text { graus }\right)\end{array}$ & 592 & 7,3 & 1 & 1 & 1 & 1 & 1 & 1 & 1 \\
\hline Sim, durante o $1^{\circ} \mathrm{grau}$ & 273 & 8,6 & 1 & 0,8 & 0,9 & 1,4 & 0,8 & 0,8 & 0,9 \\
\hline Sim, durante o $2^{\circ}$ grau & 2982 & 9,7 & 1,1 & $0,7^{*}$ & 1,2 & $1,5^{*}$ & 1,2 & 1 & 1 \\
\hline Não & 18787 & 11,4 & 1,1 & 0,9 & $1,5^{*}$ & 1,4 & 1,1 & 1 & 1 \\
\hline \multicolumn{10}{|l|}{ Carga horária de trabalho } \\
\hline Não trabalha & 12308 & 11,6 & 1 & 1 & 1 & 1 & 1 & 1 & 1 \\
\hline $\begin{array}{l}\text { Até } 20 \text { horas semanais } \\
\text { manhã ou tarde }\end{array}$ & 829 & 11,1 & $0,8^{*}$ & 0,8 & $0,7^{*}$ & $0,6^{*}$ & 0,8 & 0,8 & $0,7^{*}$ \\
\hline $\begin{array}{l}\text { Até } 20 \text { horas semanais, } \\
\text { à noite }\end{array}$ & 238 & 12,9 & 0,8 & 0,8 & 0,7 & 0,8 & 1,3 & $0,5^{*}$ & 1 \\
\hline $\begin{array}{l}\text { De } 20 \text { a } 30 \text { horas semanais, } \\
\text { manhã e tarde }\end{array}$ & 383 & 11,9 & $0,7^{*}$ & $0,7^{*}$ & $0,5^{*}$ & 0,9 & $0,6^{*}$ & $0,7^{*}$ & $0,8^{*}$ \\
\hline $\begin{array}{l}\text { De } 20 \text { a } 30 \text { horas semanais, } \\
\text { tarde e noite }\end{array}$ & 229 & 11,5 & $0,7^{*}$ & 1 & $0,6^{*}$ & $0,5^{*}$ & $0,6^{*}$ & 0,8 & $0,7^{*}$ \\
\hline $\begin{array}{l}\text { De } 20 \text { a } 30 \text { horas semanais, } \\
\text { manhã e noite }\end{array}$ & 100 & 11,9 & $0,7^{*}$ & 0,5 & $0,5^{*}$ & 0,8 & 0,6 & 0,9 & 0,6 \\
\hline $\begin{array}{l}40 \text { horas semanais, } \\
\text { manhã e tarde }\end{array}$ & 832 & 10,4 & $0,5^{*}$ & $0,5^{*}$ & $0,4^{*}$ & 1 & $0,6^{*}$ & $0,6^{*}$ & $0,6^{*}$ \\
\hline $\begin{array}{l}40 \text { horas semanais, } \\
\text { manhã e noite }\end{array}$ & 258 & 9 & $0,5^{*}$ & 0,9 & 0,6 & $0,5^{*}$ & 1 & $0,5^{*}$ & $0,5^{*}$ \\
\hline $\begin{array}{l}40 \text { horas semanais, } \\
\text { tarde e noite }\end{array}$ & 175 & 10,4 & $0,6^{*}$ & $0,6^{*}$ & $0,4^{*}$ & $0,4^{*}$ & 0,7 & $0,7^{*}$ & $0,7^{*}$ \\
\hline Trabalha por turno & 412 & 11,5 & $0,6^{*}$ & $0,7^{*}$ & $0,5^{*}$ & $0,7^{*}$ & $0,5^{*}$ & 0,8 & $0,7^{*}$ \\
\hline Trabalha eventualmente & 447 & 12,6 & $0,8^{*}$ & $0^{*}$ & $0^{*}$ & $0,6^{*}$ & $0,7^{*}$ & 0,9 & 0,9 \\
\hline \multicolumn{10}{|l|}{ Chefe } \\
\hline O pai & 12396 & 11,1 & 1 & 1 & 1 & 1 & 1 & 1 & 1 \\
\hline A mãe & 6492 & 11,2 & 1 & 1 & 0,9 & 1,1 & 1 & 1 & 1,1 \\
\hline O cônjuge & 1085 & 8 & $0,8^{*}$ & 0,8 & 1,1 & 0,9 & $0,7^{*}$ & $0,8^{*}$ & 0,9 \\
\hline Um parente & 762 & 9,9 & 1 & 1,2 & 0,9 & 0,9 & 1,1 & 0,9 & 1 \\
\hline Você próprio & 1468 & 11,9 & $1,3^{*}$ & 1,3 & $1,7^{*}$ & $1,5^{*}$ & 1,2 & 1,1 & $1,4^{*}$ \\
\hline Outra pessoa & 405 & 10,7 & 1,1 & 0,9 & 1,2 & 1 & 1,1 & 1,1 & 1 \\
\hline \multicolumn{10}{|l|}{$\begin{array}{l}\text { Situação de trabalho do } \\
\text { cônjuge }\end{array}$} \\
\hline Vive de renda & 60 & 6,9 & 1 & 1 & 1 & 1 & 1 & 1 & 1 \\
\hline $\begin{array}{l}\text { Não tem cônjuge ou } \\
\text { companheiro(a) }\end{array}$ & 19803 & 11,5 & $1,7^{*}$ & 1,9 & 1,2 & 1 & 2,9 & 1,6 & $2,3^{*}$ \\
\hline $\begin{array}{l}\text { Trabalha em casa, sem } \\
\text { remuneração formal }\end{array}$ & 443 & 8,6 & 1,2 & 1,3 & 0,8 & 0,8 & 2,2 & 1,2 & 1,6 \\
\hline É estudante & 522 & 7,8 & 1,1 & 0,9 & 0,6 & 0,7 & 2,3 & 1,1 & 1,9 \\
\hline $\begin{array}{l}\text { Trabalha (exerce atividade } \\
\text { remunerada) }\end{array}$ & 1054 & 7,9 & 1,1 & 1,2 & 0,6 & 0,7 & 2,4 & 1,1 & 1,6 \\
\hline $\begin{array}{l}\text { Trabalha (exerce atividade } \\
\text { remunerada) e estuda }\end{array}$ & 401 & 9,5 & 1,3 & 1,3 & 0,7 & 0,6 & 2,6 & 1,2 & 1,9 \\
\hline Está desempregado(a) & 181 & 8 & 1,2 & 1,1 & 0,9 & 0,4 & 1,6 & 1,3 & 1,8 \\
\hline É aposentado(a) & 137 & 6,1 & 0,9 & 1 & 0,6 & 0,5 & 1,3 & 0,9 & 1,4 \\
\hline
\end{tabular}

Est. Aval. Educ., São Paulo, v. 21, n. 45, p. 67-86, jan./abr. 2010 • 77 


\begin{tabular}{|c|c|c|c|c|c|c|c|c|c|}
\hline & \multicolumn{2}{|c|}{ Aprovados } & \multicolumn{7}{|c|}{ Modelo Logístico Múltiplo } \\
\hline & Sim & $\%$ & Geral & 03 & 04 & 05 & 06 & 07 & 08 \\
\hline \multicolumn{10}{|l|}{ Curso e Concorrência } \\
\hline Exatas_Alta & 431 & 7 & 1 & 1 & 1 & 1 & 1 & 1 & 1 \\
\hline Exatas_Média & 5137 & 14,7 & $2,1^{*}$ & $3,1^{*}$ & $2,9^{*}$ & $2,1^{*}$ & $2,4^{*}$ & $1,9^{*}$ & 1,3 \\
\hline Exatas_Baixa & 912 & 25,8 & $4,8^{*}$ & $8,4^{*}$ & $6,8^{*}$ & $4,4^{*}$ & $5,3^{*}$ & $4,8^{*}$ & $3^{*}$ \\
\hline Biológicas e Saúde_Alta & 963 & 3,5 & $0,3^{*}$ & $0,5^{*}$ & $0,3^{*}$ & $0,3^{*}$ & $0,4^{*}$ & $0,3^{*}$ & $0,2^{*}$ \\
\hline Biológicas e Saúde_Média & 4261 & 8,8 & $1,4^{*}$ & $1,8^{*}$ & $1,6^{*}$ & 1,3 & $1,5^{*}$ & $1,5^{*}$ & 1,1 \\
\hline Biológicas e Saúde_Baixa & 1438 & 21,6 & $5,3^{*}$ & $9,3^{*}$ & $7,5^{*}$ & $5,1^{*}$ & $6,4^{*}$ & $5^{*}$ & $3,2^{*}$ \\
\hline Humanas e Letras_Alta & 2960 & 6 & $0,8^{*}$ & 0,8 & 0,9 & 0,8 & 0,8 & 0,8 & $0,5^{*}$ \\
\hline Humanas e Letras_Média & 7136 & 16,1 & $3,1^{*}$ & $4,1^{*}$ & $4,1^{*}$ & $2,5^{*}$ & $3,4^{*}$ & $3,1^{*}$ & $2,2^{*}$ \\
\hline Humanas e Letras_Baixa & 420 & 44,6 & $1,5^{*}$ & $0^{*}$ & $0^{*}$ & $0^{*}$ & $0^{*}$ & $16,1^{*}$ & $13,8^{*}$ \\
\hline Artes_Alta & 518 & 10,8 & $1,6^{*}$ & $2,3^{*}$ & $2,3^{*}$ & $1,7^{*}$ & $1,8^{*}$ & $1,5^{*}$ & 1 \\
\hline Artes_Média & 1182 & 23,4 & $5,1^{*}$ & $9,2^{*}$ & $9,2^{*}$ & $4,2^{*}$ & $5,2^{*}$ & $4,5^{*}$ & $3,3^{*}$ \\
\hline Artes_Baixa & 106 & 35 & $8^{*}$ & $10,6^{*}$ & $12,9^{*}$ & $7,8^{*}$ & $8,9^{*}$ & $5,9^{*}$ & $7,4^{*}$ \\
\hline \multicolumn{10}{|l|}{ Ano de inscrição } \\
\hline 2003 & 3845 & 9,9 & 1 & & & & & & \\
\hline 2004 & 3892 & 10,3 & $1,5^{*}$ & & & & & & \\
\hline 2005 & 3986 & 12,1 & $1,6^{*}$ & & & & & & \\
\hline 2006 & 3993 & 9,9 & $1,5^{*}$ & & & & & & \\
\hline 2007 & 4672 & 10,9 & $1,5^{*}$ & & & & & & \\
\hline 2008 & 5076 & 12,9 & $1,8^{*}$ & & & & & & \\
\hline \multicolumn{10}{|l|}{ No de vestibular na UFBA } \\
\hline Nenhuma vez & 8019 & 7,7 & 1 & 1 & 1 & 1 & 1 & 1 & 1 \\
\hline Uma vez & 7464 & 14 & $1,9^{*}$ & $1,9^{*}$ & $1,7^{*}$ & $2,1^{*}$ & $1,9^{*}$ & $2,2^{*}$ & $1,9^{*}$ \\
\hline Duas vezes & 4031 & 14,7 & $2,1^{*}$ & $1,8^{*}$ & $1,8^{*}$ & $2,7^{*}$ & $2^{*}$ & $2,5^{*}$ & $2,3^{*}$ \\
\hline Três vezes & 1841 & 14,1 & $2,2^{*}$ & $1,9^{*}$ & $1,7^{*}$ & $3,1^{*}$ & $2^{*}$ & $2,4^{*}$ & $2,4^{*}$ \\
\hline Quatro vezes ou mais & 1311 & 13,6 & $2,2^{*}$ & $2^{*}$ & $2^{*}$ & $3,4^{*}$ & $1,9^{*}$ & $2,4^{*}$ & $2,3^{*}$ \\
\hline \multicolumn{10}{|l|}{ Cursinho } \\
\hline Não fiz cursinho & 9662 & 10,3 & 1 & 1 & 1 & 1 & 1 & 1 & 1 \\
\hline Fiz cursinho & 12997 & 11,5 & $1,2^{*}$ & 0,9 & 1,1 & 1,1 & $1,2^{*}$ & $1,2^{*}$ & $1,3^{*}$ \\
\hline \multicolumn{10}{|l|}{$\begin{array}{l}\text { Quem influenciou na escolha } \\
\text { do curso }\end{array}$} \\
\hline $\begin{array}{l}\text { Ninguém (ou nada) o } \\
\text { influenciou }\end{array}$ & 8288 & 9,6 & 1 & 1 & 1 & 1 & 1 & 1 & 1 \\
\hline Pai e/ou mãe & 1076 & 8,2 & 0,9 & 0,9 & 1 & 0,9 & 0,9 & 0,8 & 0,9 \\
\hline Professor & 567 & 14,2 & $1,5^{*}$ & 1,1 & $1,6^{*}$ & $1,7^{*}$ & 1,2 & 1,3 & $1,6^{*}$ \\
\hline $\begin{array}{l}\text { Cônjuge, irmão, amigos ou } \\
\text { parentes }\end{array}$ & 851 & 9,8 & 1 & 1,3 & 1,2 & 0,9 & 0,9 & 1 & 1,1 \\
\hline $\begin{array}{l}\text { Seção de Orientação - SSOA } \\
\text { - UFBA }\end{array}$ & 148 & 11,2 & 1,1 & 0,9 & 1,2 & 1 & 1,4 & 1 & 1,1 \\
\hline $\begin{array}{l}\text { Orientador educacional de } \\
\text { minha escola }\end{array}$ & 150 & 7,9 & 0,8 & 0,9 & 0,7 & 0,9 & 0,8 & 1 & $0,6^{*}$ \\
\hline $\begin{array}{l}\text { Serviço de teste vocacional } \\
\text { Informação dos meios de }\end{array}$ & 605 & 8,1 & 0,9 & 0,8 & 0,8 & 0,8 & 0,9 & 0,8 & 0,9 \\
\hline $\begin{array}{l}\text { comunicação, livros e } \\
\text { palestras }\end{array}$ & 4132 & 12,1 & $1,3^{*}$ & $1,3^{*}$ & $1,4^{*}$ & $1,5^{*}$ & $1,2^{*}$ & $1,2^{*}$ & $1,3^{*}$ \\
\hline Ambiente de trabalho & 1157 & 11,4 & $1,3^{*}$ & $1,3^{*}$ & 1,1 & $1,4^{*}$ & 1,2 & $1,4^{*}$ & 1,1 \\
\hline Outras influências & 4682 & 14,1 & $1,4^{*}$ & $1,5^{*}$ & $1,3^{*}$ & $1,3^{*}$ & $1,4^{*}$ & $1,4^{*}$ & $1,5^{*}$ \\
\hline
\end{tabular}

78 - Est. Aval. Educ., São Paulo, v. 21, n. 45, p. 67-86, jan./abr. 2010 


\begin{tabular}{|c|c|c|c|c|c|c|c|c|c|}
\hline & \multicolumn{2}{|c|}{ Aprovados } & \multicolumn{7}{|c|}{ Modelo Logístico Múltiplo } \\
\hline & Sim & $\%$ & Geral & 03 & 04 & 05 & 06 & 07 & 08 \\
\hline \multicolumn{10}{|l|}{ Expectativa do curso superior } \\
\hline $\begin{array}{l}\text { Aumento de conhecimento, } \\
\text { cultura geral e consciência } \\
\text { crítica }\end{array}$ & 7789 & 12,8 & 1 & 1 & 1 & 1 & 1 & 1 & 1 \\
\hline $\begin{array}{l}\text { Formação profissional para o } \\
\text { futuro emprego }\end{array}$ & 10318 & 9,8 & $0,8^{*}$ & 1 & 1 & $0,8^{*}$ & $0,8^{*}$ & $0,8^{*}$ & $0,7^{*}$ \\
\hline $\begin{array}{l}\text { Melhoria de situação } \\
\text { profissional ou econômica }\end{array}$ & 1739 & 10,3 & $0,8^{*}$ & 1 & 1,2 & $0,7^{*}$ & $0,8^{*}$ & $0,7^{*}$ & $0,8^{*}$ \\
\hline Outro & 2813 & 11,7 & 1,1 & $1,5^{*}$ & $1,4^{*}$ & 0,9 & $0,5^{*}$ & 0,7 & 0,7 \\
\hline \multicolumn{10}{|l|}{$\begin{array}{l}\text { Pretende trabalhar cursando } \\
\text { a faculdade }\end{array}$} \\
\hline $\begin{array}{l}\text { Sim, desde o primeiro ano, } \\
\text { em tempo integral }\end{array}$ & 1234 & 9,4 & 1 & 1 & 1 & 1 & 1 & 1 & 1 \\
\hline $\begin{array}{l}\text { Sim, desde o primeiro ano, } \\
\text { em tempo parcial }\end{array}$ & 8915 & 11,6 & $1,3^{*}$ & 1,3 & 1,2 & $1,4^{*}$ & 1,2 & $1,4^{*}$ & 1,1 \\
\hline $\begin{array}{l}\text { Sim, apenas nos últimos } \\
\text { anos }\end{array}$ & 1622 & 13 & $1,4^{*}$ & $1,4^{*}$ & $1,5^{*}$ & $1,4^{*}$ & $1,4^{*}$ & $1,6^{*}$ & 1,2 \\
\hline $\begin{array}{l}\text { Sim, apenas em estágio para } \\
\text { treinamento }\end{array}$ & 9124 & 10,7 & $1,2^{*}$ & $1,4^{*}$ & 1,2 & 1,1 & 1,1 & $1,3^{*}$ & 1 \\
\hline Não & 1715 & 8,9 & 1 & 1 & 1,1 & 1,1 & 1 & 1,2 & 0,9 \\
\hline \multicolumn{10}{|l|}{ Sexo } \\
\hline Feminino & 12763 & 9,6 & & & & & & & \\
\hline Masculino & 12701 & 12,8 & $1,2^{*}$ & $1,2^{*}$ & 1,2 & $1,2^{*}$ & $1,2^{*}$ & $1,4^{*}$ & $1,2^{*}$ \\
\hline \multicolumn{10}{|l|}{ Residência atual } \\
\hline $\begin{array}{l}\text { Interior do Estado da Bahia } \\
\text { Salvador e área }\end{array}$ & 4267 & 9,5 & 1 & 1 & 1 & 1 & 1 & 1 & 1 \\
\hline metropolitana & 17903 & 11,4 & $1,1^{*}$ & $1,3^{*}$ & $1,5^{*}$ & $1,3^{*}$ & $1,2^{*}$ & 1 & 1,1 \\
\hline Outro Estado & 503 & 8,3 & 1 & 0,9 & 0,8 & 1,1 & 1,1 & 1,1 & 1,1 \\
\hline \multicolumn{10}{|l|}{ Cor/raça } \\
\hline Preta & 3992 & 9,8 & 1 & 1 & 1 & 1 & 1 & 1 & 1 \\
\hline Branca & 5953 & 11,6 & $1,2^{*}$ & 1,2 & $1,4^{*}$ & $1,4^{*}$ & $1,3^{*}$ & $1,2^{*}$ & 1 \\
\hline Parda & 11655 & 11,1 & $1,2^{*}$ & 1 & $1,2^{*}$ & $1,4^{*}$ & $1,2^{*}$ & $1,2^{*}$ & 1 \\
\hline Amarela & 503 & 8,9 & 1 & 0,8 & 1,2 & 1,1 & 1 & 0,9 & 0,8 \\
\hline Indígena & 487 & 11,5 & $1,2^{*}$ & 0,9 & 1 & $1,7^{*}$ & $1,4^{*}$ & 1,2 & 1,1 \\
\hline
\end{tabular}

\section{IMPACTO DO SISTEMA DE COTAS}

Supondo a inexistência de um sistema de cotas no processo seletivo da UFBA, este estudo atribuiu o resultado de aprovado aos alunos com maiores desempenhos no vestibular, independentemente de qualquer característica (cor/raça ou rede de ensino do $2^{\circ}$ grau), de acordo com o número de vagas de cada curso. Assim, considerando algumas características dos candidatos, foram calculados os percentuais de aprovação, de 2005 a 2008, sem o sistema de cotas, e colocados em um mesmo gráfico com os reais percentuais de aprovação com o sistema de cotas. 
Nas figuras a seguir, as linhas pontilhadas referem-se à situação fictícia em que os alunos são aprovados mediante apenas seu desempenho no vestibular, e as linhas contínuas representam a situaçấo real, considerando o sistema de cotas. A figura 3 apresenta o percentual de aprovação dos candidatos por nível de instrução da mãe. Foi observado que o percentual de aprovação dos candidatos cuja mãe tem até o $2^{\circ}$ grau completo aumentou, enquanto a aprovaçáo dos candidatos cuja máe tem o nível superior completo caiu. Além disso, a distância entre os percentuais de aprovação dos candidatos com essas duas características vai diminuindo ao longo dos anos, mostrando mais uma vez uma tendência à equidade. A mesma interpretaçáo pode ser dada, em relação à ocupação do pai (figura 4), em que a aprovação média dos candidatos cujos pais trabalham em cargos de nível superior está mais próxima do percentual médio de aprovação dos candidatos cujos pais trabalham em outros cargos. Além disso, essa aproximação vem aumentando ao longo dos anos.

Figura 3 - Nível educacional da mãe

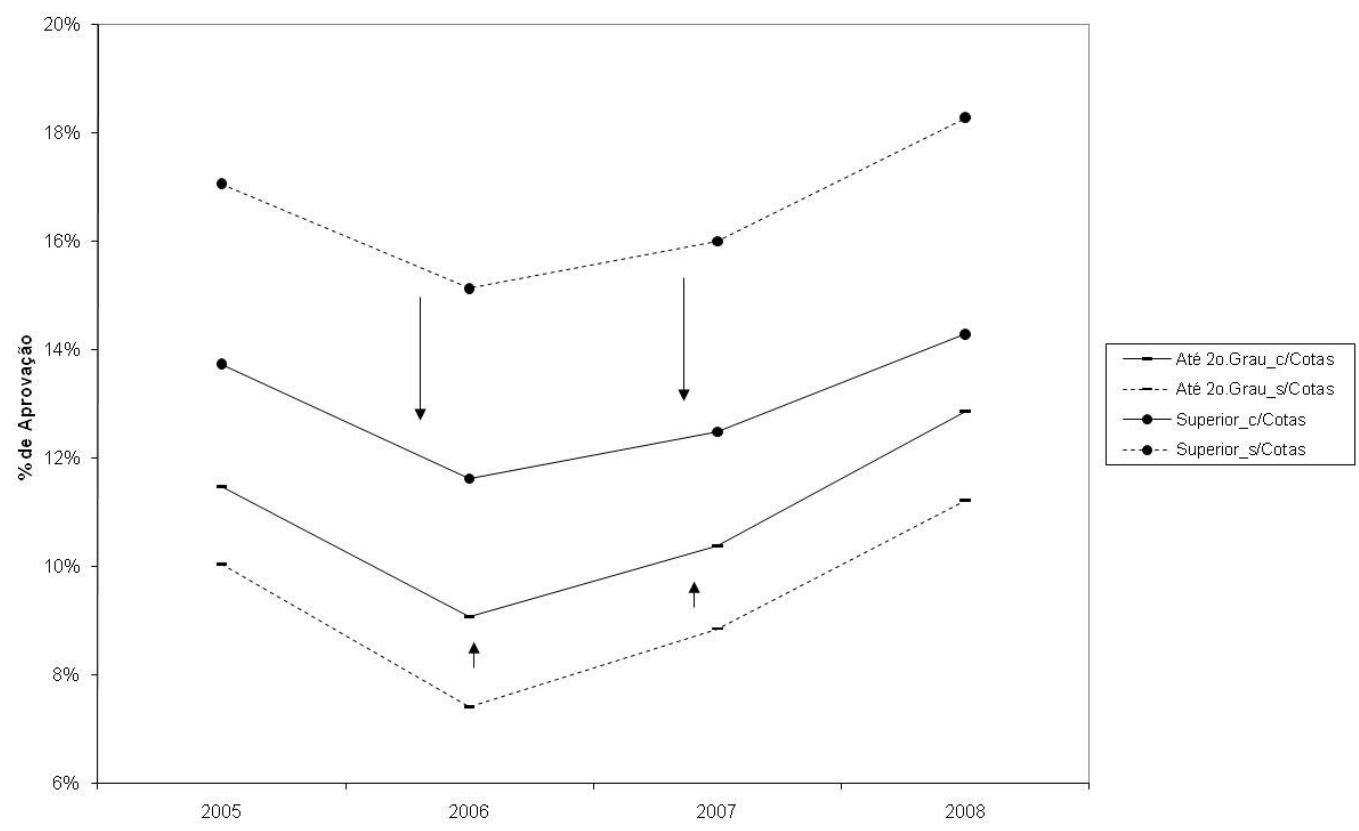

80 - Est. Aval. Educ., São Paulo, v. 21, n. 45, p. 67-86, jan./abr. 2010 
Figura 4 - Ocupação do pai

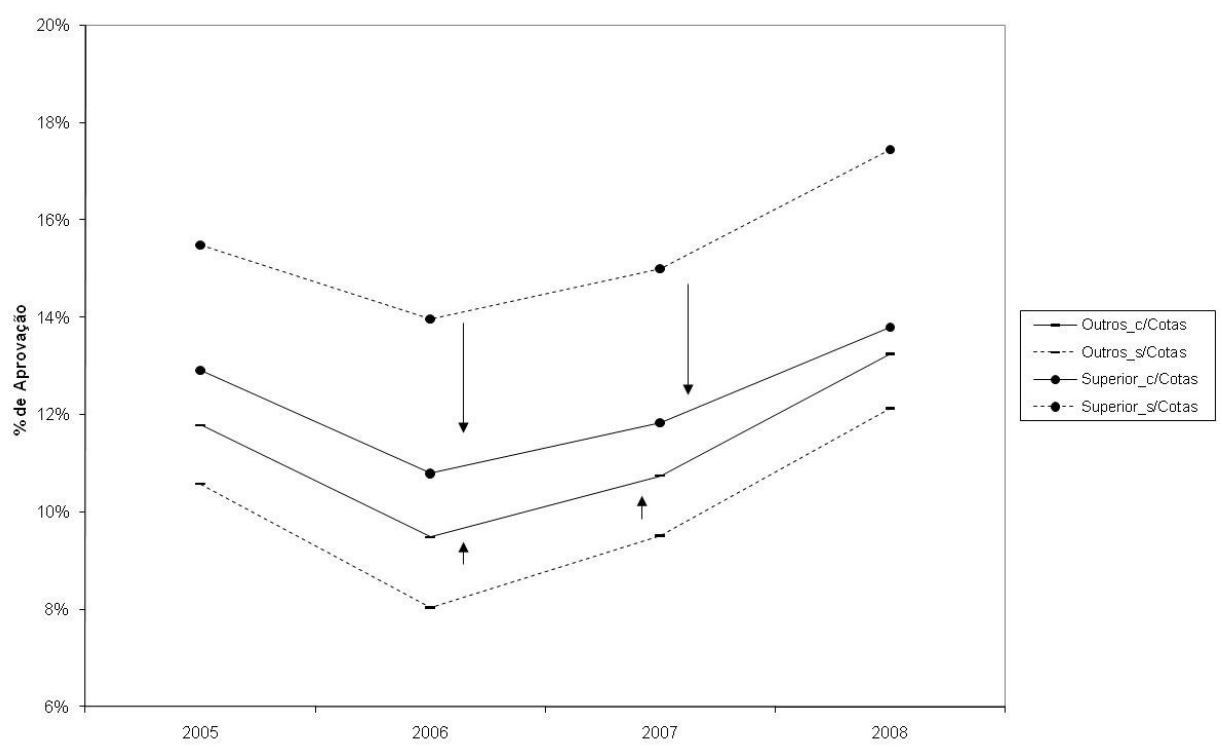

Já na figura 5, além de se observar que os percentuais de aprovação dos candidatos negros (considerados aqui como negros e pardos) e brancos estão mais próximos, também se verifica uma inversão em que a aprovação dos negros se tornara maior em 2008, fato que não aconteceria se o resultado no vestibular dependesse apenas do desempenho dos candidatos nos testes.

Figura 5 - Cor/Raça

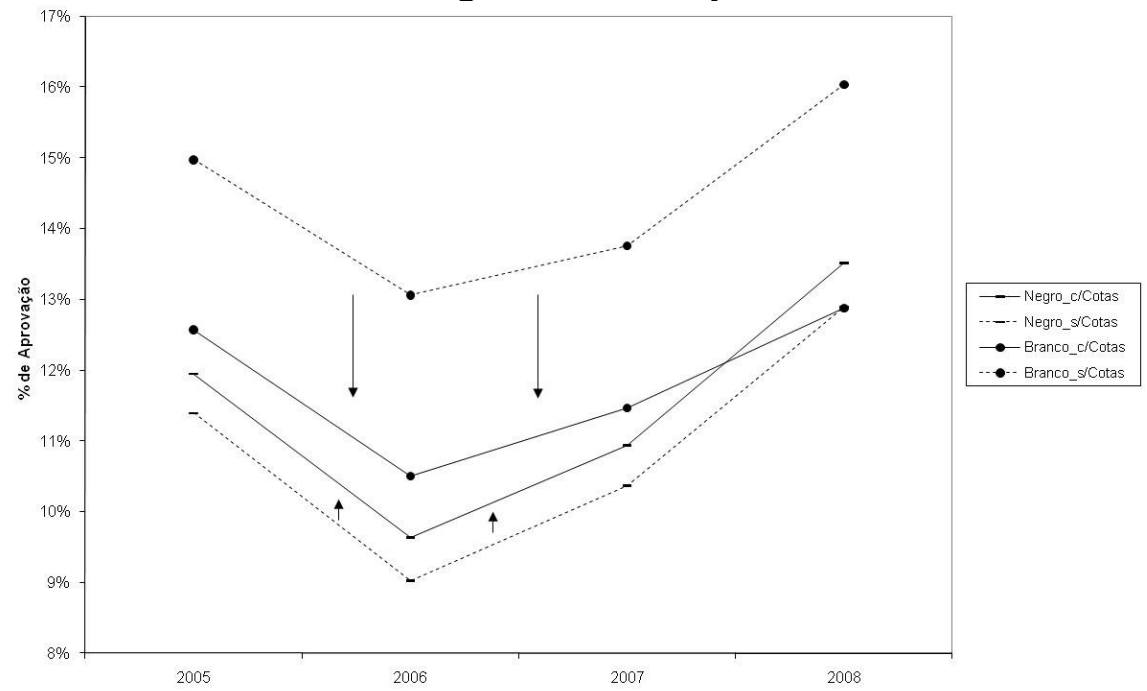

Est. Aval. Educ., São Paulo, v. 21, n. 45, p. 67-86, jan./abr. 2010 • 81 
A figura 6 mostra que o sistema de cotas permitiu que candidatos oriundos de escolas públicas (estaduais e municipais) tivessem as mesmas chances de aprovação no vestibular que os candidatos de escolas particulares. Entretanto, os candidatos oriundos de escolas federais, que antes já apresentavam melhores resultados no vestibular, tiveram suas chances potencializadas com o sistema de cotas.

Figura 6 - Rede de ensino do $2^{\circ}$ grau

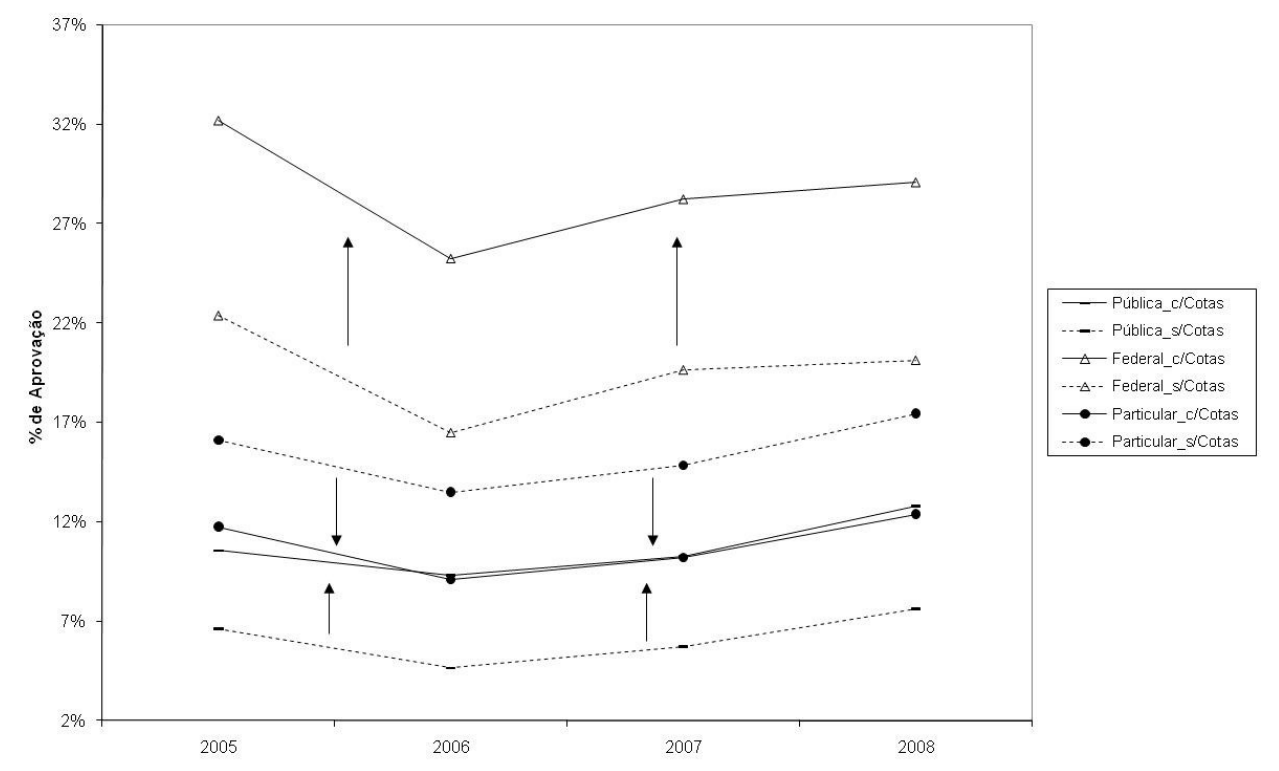

Outro resultado interessante é quanto à idade média dos candidatos inscritos no vestibular. Se não houvesse o sistema de cotas, os candidatos aprovados seriam sempre mais novos que os reprovados, em todos os anos (Figura 7). Entretanto, com o vestibular atual, pode-se observar que no início dos anos estudados, a idade dos candidatos aprovados era menor, porém isso foi se invertendo ao longo dos anos, até que em 2008 os candidatos aprovados eram, em média, mais velhos (Figura 8).

82 - Est. Aval. Educ., São Paulo, v. 21, n. 45, p. 67-86, jan./abr. 2010 
Figura 7 - Idade média por resultado no vestibular da UFBA sem o sistema de cotas

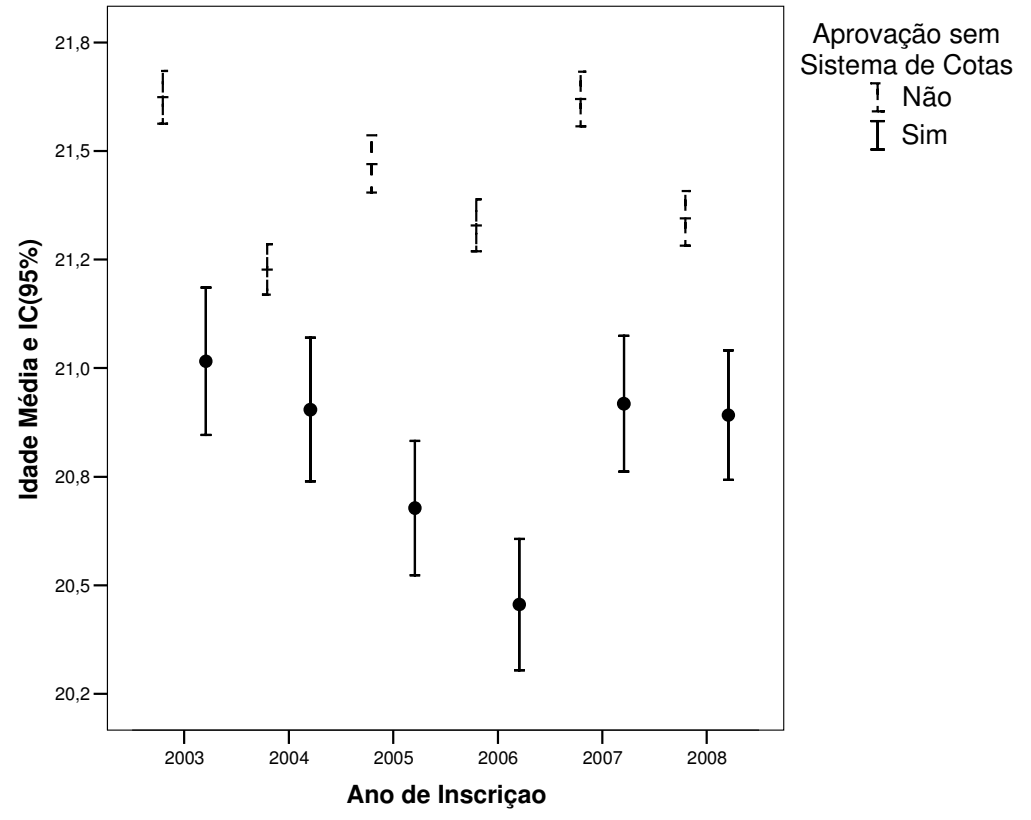

Figura 8 - Idade média por resultado no vestibular da UFBA

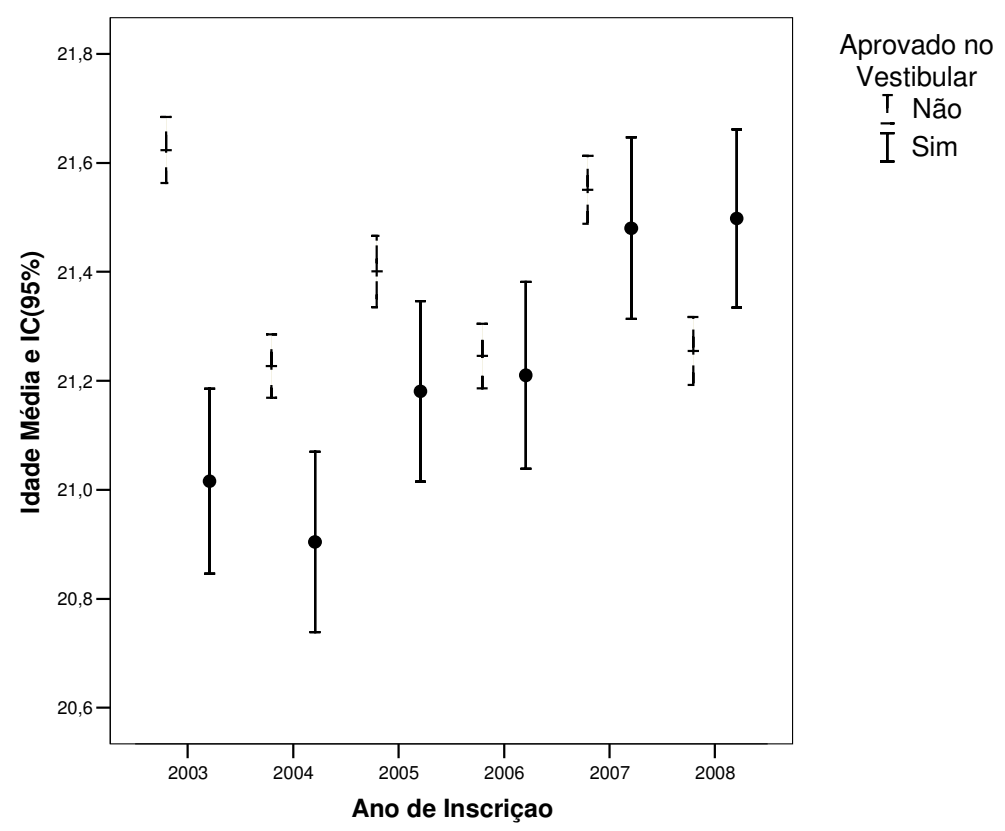

Est. Aval. Educ., São Paulo, v. 21, n. 45, p. 67-86, jan./abr. 2010 • 83 


\section{CONCLUSÃO}

A Ação Afirmativa no Vestibular da Universidade Federal da Bahia teve início em 2005, com a implantaçáo de um sistema de reserva de vagas (cotas) para alunos originários da escola pública que se declaram pretos, pardos, índio-descendentes ou de outros grupos étnicos. Este trabalho teve o objetivo de avaliar o sistema de cotas e, para tanto, utilizou dados do vestibular de 2003 a 2008. Primeiramente, foi ajustado um modelo logístico para cada característica do candidato, sendo a variável resposta a aprovação ou não no vestibular. Nessa etapa, foi observado que a maioria das varáveis independentes apresentou iteração significativa com o ano de inscrição no vestibular, porém o programa de cotas apenas mostrou influência para as seguintes variáveis: renda (categorias "maior que 1 até 3 salários mínimos" e "maior que 3 até 5 salários mínimos"), nível de educaçáo do pai (categorias "primário incompleto", "ginásio incompleto" e "ginásio completo"), nível educacional da mãe (categoria "ginásio incompleto"), rede de ensino em que estudou o $2^{\circ}$ grau (categoria "escola estadual") e trabalhou durante os estudos (categoria "sim, durante o $2^{\circ}$ grau"). Ainda nessa etapa, foi verificado que as variáveis "principal ocupação" e "estado civil" não foram significativas (ao nível de 5\%).

Em seguida, foi ajustado um modelo logístico múltiplo com todas as variáveis que foram significativas na etapa anterior e, dentre alguns resultados encontrados, foi observado que a variável raça/cor, a partir desse ano de 2005, apresentou uma tendência à equidade, isto é, independentemente da etnia, os candidatos tendem a ter as mesmas chances de serem aprovados no vestibular.

Ao se criar uma situação hipotética em que o resultado do vestibular só dependesse do desempenho dos candidatos nos testes, foi constatado que o sistema de cotas tornou os percentuais de aprovaçáo mais próximos entre os candidatos de diferentes características, como entre os candidatos de escolas particulares e públicas (municipais e estaduais) e entre as raças negra e branca.

\section{REFERÊNCIAS BIBLIOGRÁFICAS}

ALLISON, P. D. Logistic regression using the SAS System: theory and application Cary, NC: SAS Institute Inc., 1999.

BRASIL. Ministério da Educação. Instituto Nacional de Estudos e Pesquisas Educacionais Anísio Teixeira. Sinopses Estatísticas da Educação Superior - Graduação. Brasília, 2005
Disponível em: <http://www.inep.gov.br/ superior/censosuperior/ sinopse/>. Acesso em: 28 de abr. 2009.

CORRAR, L. J.; THEÓPHILO, C. R. Pesquisa operacional para decisão em contabilidade e administração: contabilometria. 1. ed. São Paulo: Atlas, 2004.

84 - Est. Aval. Educ., São Paulo, v. 21, n. 45, p. 67-86, jan./abr. 2010 
DACHS, J. N. W.; MAIA R. P. Subsídios quantitativos para repensar as políticas de acesso à universidade: aumentando a equidade racial e econômica no ensino de terceiro grau no Brasil e no Estado de São Paulo. 2006. Disponível em: <www.nepp. unicamp.br/Cadernos/Caderno74.pdf $>$. Acesso em: 28 abr. 2009.

FAMÁ, R.; MELHER, S. Estrutura de capital na América Latina: existiria uma correlação com o lucro das empresas? São Paulo: USP, 1999.
NEWSO, M. More on model fit and significance of predictors with logistic regression. 2005. Disponível em: <http://www.upa.pdx.edu/ IOA/ newsom/da2/ho_logistic3.doc $>$. Acesso em: 28 abr. 2009.

SILVA, E. R. Aplicação de metodologia de dados em painel em modelos de behaviour score do varejo. 2006. Disponível em: <http://tede.ibmecsp.edu.br/tde_busca/ arquivo.php?codArquivo $=45>$. Acesso em: 28 abr. 2009.

Recebido em: setembro 2009

Aprovado para publicação em: fevereiro 2010 